Supporting Information

\title{
Luminescent Helical Nanofiber Self-Assembled from a Cholesterol-Based Metalloamphiphile and Its Application in DNA Conformation Recognition
}

\author{
Hairui Lei, Jing Liu, Junlin Yan, Jingmiao Quan and Yu Fang
}

Key Laboratory of Applied Surface and Colloid Chemistry, Ministry of Education, School of Chemistry \& Chemical Engineering, Shaanxi Normal University, Xi'an 710062, People's Republic of China

*E-mail: jliu@ snnu.edu.cn

\section{Contents list}

$\begin{array}{lll}\text { 1. FTIR spectra of Ligand(I) and }[\mathrm{TbL}(\mathrm{I})] \mathrm{Cl}_{3} & \mathrm{~S} 2\end{array}$

2. Determination of critical aggregation concentration for $[\mathrm{TbL}(\mathrm{I})] \mathrm{Cl}_{3} \quad \mathrm{~S} 3$

3. CD spectra of $[\mathrm{TbL}(\mathrm{I})] \mathrm{Cl}_{3}$ and the hydrochloride salt of compound $4 \quad \mathrm{~S} 3$

4. Molecular dynamics simulation for the length of $\mathrm{TbL}^{3+}(\mathbf{I}) \quad \mathrm{S} 3$

5. Photophysical characteristics of $[\mathrm{TbL}(\mathrm{I})] \mathrm{Cl}_{3} \quad \mathrm{~S} 4$

6. ${ }^{1} \mathrm{H}$ NMR spectra of guanosine and guanine tetrad S5

7. Zeta potential evolution of $[\mathrm{TbL}(\mathrm{I})] \mathrm{Cl}_{3} \quad \mathrm{~S} 5$

8. Luminescence spectra of $[\mathrm{TbL}(\mathrm{I})] \mathrm{Cl}_{3} \quad \mathrm{~S} 6$

$\begin{array}{lll}\text { 9. CD spectra of various G-rich ssDNA } & \text { S7 }\end{array}$

10. Luminescence spectra of $[\mathrm{TbL}(\mathrm{I})] \mathrm{Cl}_{3} / \mathrm{ssDNA}$ mixtures $\quad \mathrm{S} 8$

$\begin{array}{ll}\text { 11. Luminescence lifetime measurements } & \text { S9 }\end{array}$ 


\section{FTIR spectra of Ligand(I) and $[\mathrm{TbL}(\mathrm{I})] \mathrm{Cl}_{3}$}

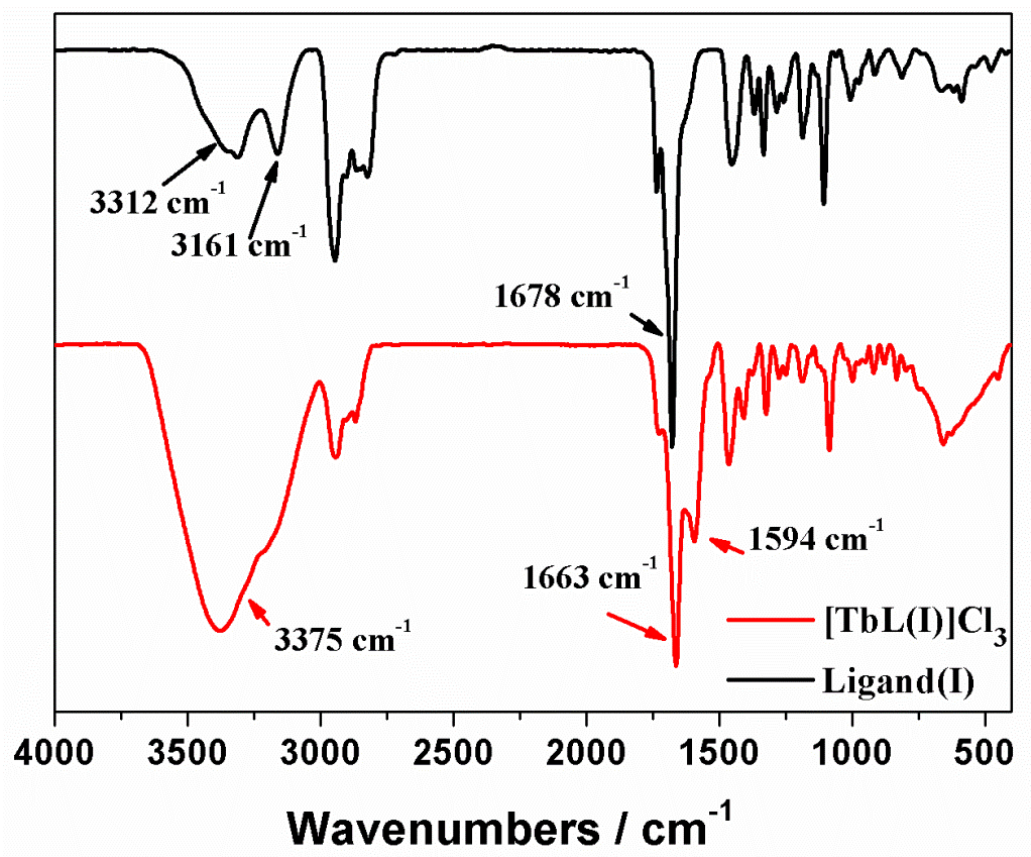

Figure S1 FT-IR spectra of ligand(I) (black) and [TbL(I)]Cl ${ }_{3}$ (red). The intense absorption bands at 1678, 3161 and $3312 \mathrm{~cm}^{-1}$ in the IR spectra of ligand(I) are attributed to the stretching vibrations of $\mathrm{C}=\mathrm{O}$ and $\mathrm{N}-\mathrm{H}$ groups. After complexing with $\mathrm{Tb}(\mathrm{III})$ ion, the stretching vibrations of $\mathrm{C}=\mathrm{O}$ group split into two peaks at 1663 and $1594 \mathrm{~cm}^{-1}$, indicating that $\mathrm{C}=\mathrm{O}$ groups coordinated to $\mathrm{Tb}(\mathrm{III})$ ions in a chelating modes. Moreover, the absorption bands of $\mathrm{N}-\mathrm{H}$ groups merged into a broad band at $3375 \mathrm{~cm}^{-1}$. This is ascribed to the stretching vibration of $\mathrm{N}-\mathrm{H}$ and $\mathrm{O}-\mathrm{H}$, indicating the presence of water molecules. 


\section{Determination of critical aggregation concentration for $[\mathrm{TbL}(\mathrm{I})] \mathrm{Cl}_{3}$}

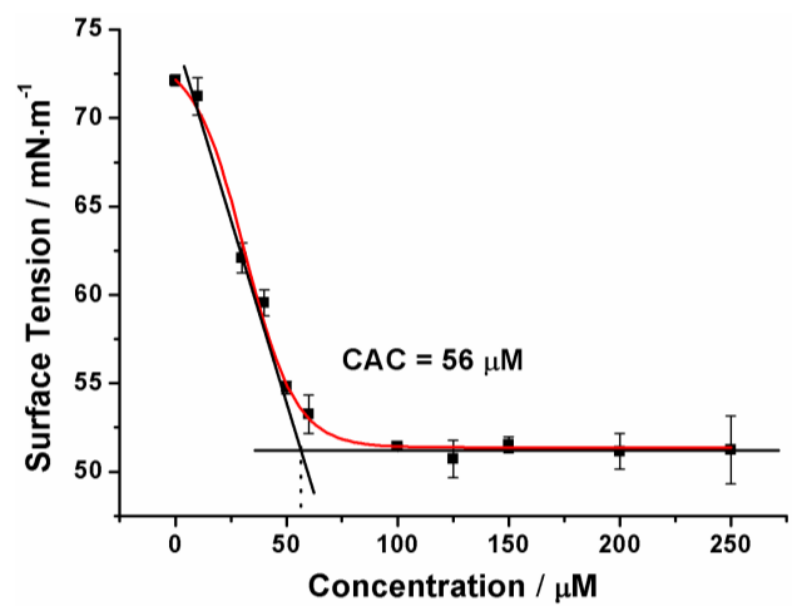

Figure S2 Surface tension as a function of the concentration of $\mathrm{TbL}^{3+}(\mathbf{I})$ in $10 \mathrm{mM}$ Tris- $\mathrm{HCl}$ buffer solutions $(\mathrm{pH}=$ 7.4). The critical aggregation concentration was determined to be $56 \mu \mathrm{M}$.

\section{CD spectra of [TbL(I)]Cl 3 and the hydrochloride salt of compound 4}
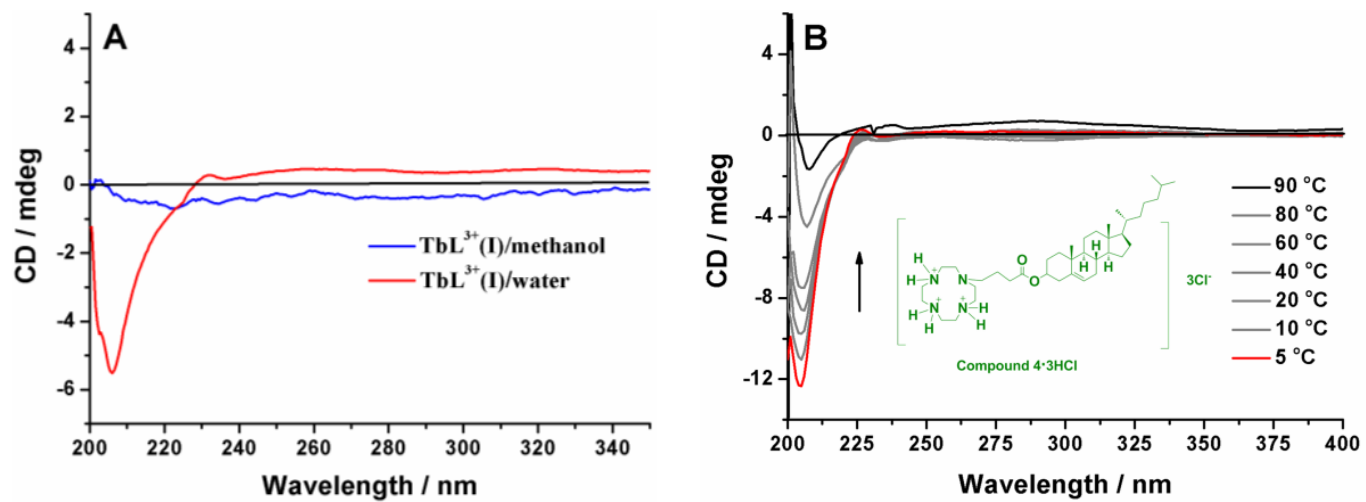

Figure S3 (A) CD spectra of $\mathrm{TbL}^{3+}(\mathbf{I})$ in $10 \mathrm{mM}$ Tris-HCl buffer solutions ( $\mathrm{pH}=7.4$, red) and methanol (blue); (B) Temperature dependent $\mathrm{CD}$ spectra of the hydrochloride salt of compound $\mathbf{4}$ in $10 \mathrm{mM}$ Tris-HCl buffer $(\mathrm{pH}=7.4)$. The concentration of $\mathrm{TbL}^{3+}(\mathbf{I})$ or the hydrochloride salt of compound 4 was $150 \mu \mathrm{M}$.

\section{Molecular dynamics simulation for the length of $\mathbf{T b L}^{3+}(\mathbf{I})$}

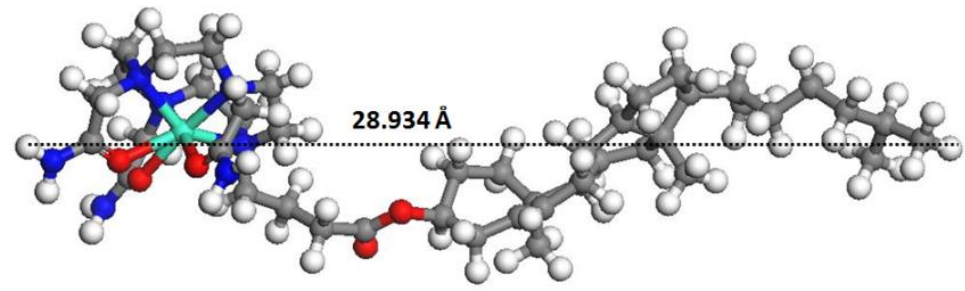

Figure S4 Molecular dynamics simulation for $\mathrm{TbL}^{3+}(\mathbf{I})$ was performed by using a software of Materials Studio. The length of $\mathrm{TbL}^{3+}(\mathbf{I})$ is about $2.9 \mathrm{~nm}$.

Molecular dynamics simulation for the conformation of $\mathrm{TbL}^{3+}(\mathbf{I})$ was performed by using a software of Materials Studio [Accelrys, MS Modeling, Release 5.0; Accelrys Software Inc.: San Diego, 2009]. The simulation 
with the $(\mathrm{N}, \mathrm{V}, \mathrm{T})$ ensemble was carried out, at $300 \mathrm{~K}$, for this system. A UNIVERSAL force field was adopted to carry out the simulation. The integration time step was set to $1 \mathrm{fs}$. At least $200 \mathrm{ps}$ molecular dynamics simulation was conducted to make ensure that the system reached its equilibrium. Then, another 100 ps molecular dynamics simulation was conducted further, and the conformation of $\mathrm{TbL}^{3+}(\mathbf{I})$ obtained at this stage was compared with that obtained in the first round simulation. It was found that there was almost no difference between the two results, indicating completion of the simulation.

\section{Photophysical characteristics of $[\mathrm{TbL}(\mathrm{I})] \mathrm{Cl}_{3}$}

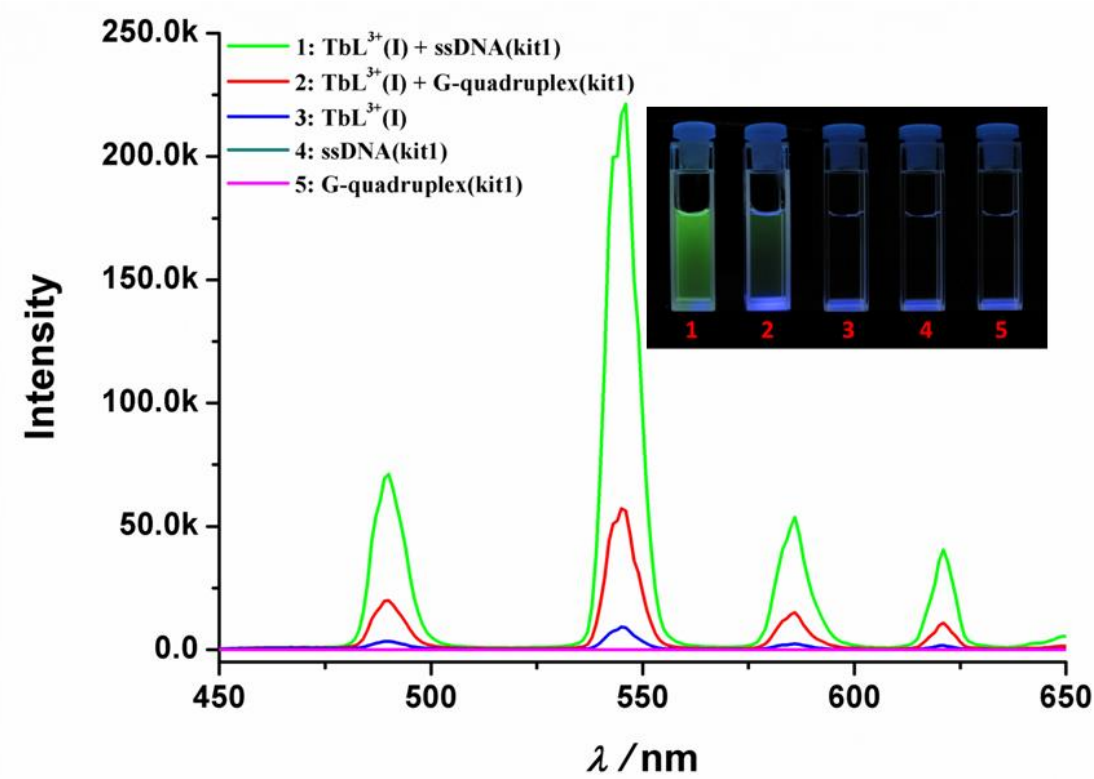

Figure S5 Luminescence spectra of $\mathrm{TbL}^{3+}(\mathbf{I})+$ ssDNA-kit1 (green), $\mathrm{TbL}^{3+}(\mathbf{I})+\mathrm{G}$-quadruplex-kit1 (red), TbL ${ }^{3+}(\mathbf{I})$ (blue), ssDNA-kit1 (cyan) and G-quadruplex-kit1 (pink). Inset: photographs of the aqueous solutions of $\mathrm{TbL}^{3+}(\mathbf{I})+$ ssDNA-kit1 (1), TbL ${ }^{3+}(\mathbf{I})+\mathrm{G}-q u a d r u p l e x-k i t 1$ (2), $\mathrm{TbL}^{3+}(\mathbf{I})$ (3), ssDNA-kit1 (4) and G-quadruplex-kit1 (5) under a $254 \mathrm{~nm}$ ultraviolet lamp. The concentration of $\mathrm{TbL}^{3+}(\mathbf{I})$ for all experiments was $150 \mu \mathrm{M}$, in $10 \mathrm{mM}$ Tris-HCl buffer $(\mathrm{pH}=7.4)$. The concentration of DNA was $1.0 \mu \mathrm{M}, \lambda_{\mathrm{ex}}=260 \mathrm{~nm}$. 


\section{6. ${ }^{1} \mathrm{H}$ NMR spectra of guanosine and guanine tetrad}

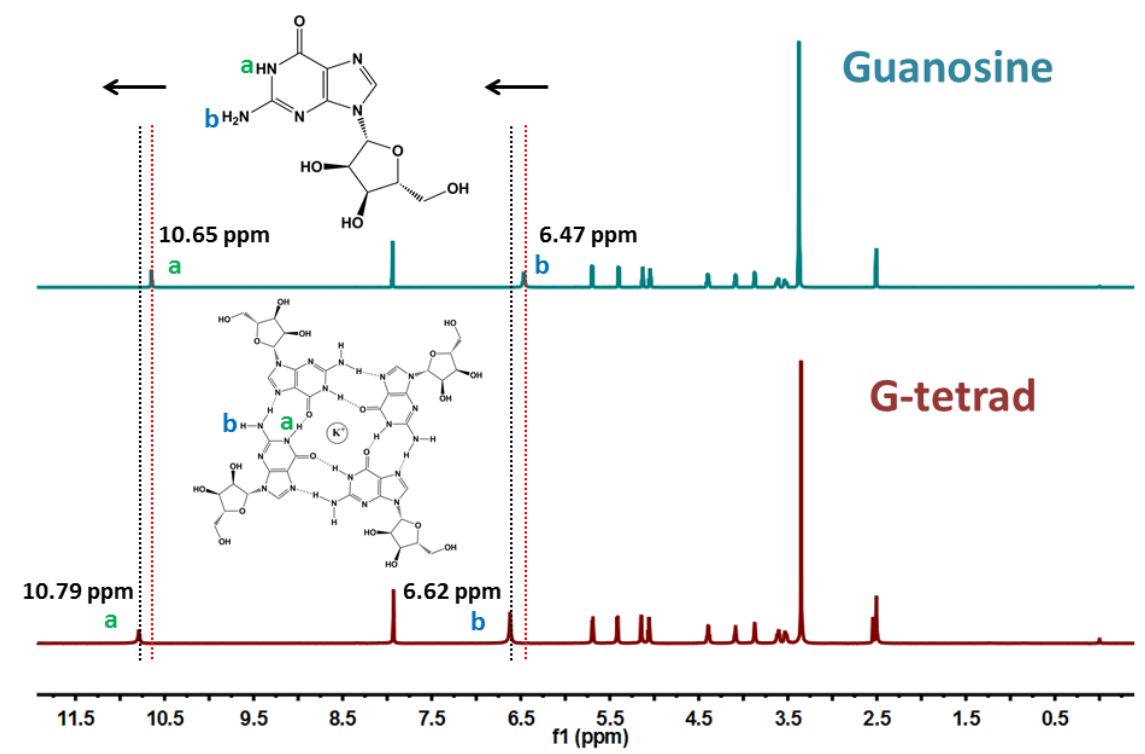

Figure S6 ${ }^{1} \mathrm{H}$ NMR spectra of guanosine in the absence and presence of $\mathrm{K}^{+}$in DMSO at $25^{\circ} \mathrm{C}$.

${ }^{1} \mathrm{H}$ NMR spectra of guanosine and guanine tetrad (G-tetrad) were measured in DMSO. To obtain the G-tetrad structure, guanosine was dissolved in $\mathrm{KCl}$ solution $(100 \mathrm{mM})$. And then, the obtained solution was heated at $95{ }^{\circ} \mathrm{C}$ for $10 \mathrm{~min}$ and cooled rapidly to $4{ }^{\circ} \mathrm{C}$. This result solution was kept at $4{ }^{\circ} \mathrm{C}$ overnight and completely evaporated to dryness. The residue was dissolved in $d$-DMSO to get a G-tetrad/ $d$-DMSO solution.

\section{Zeta potential evolution of $[\mathrm{TbL}(\mathrm{I})] \mathrm{Cl}_{3}$}

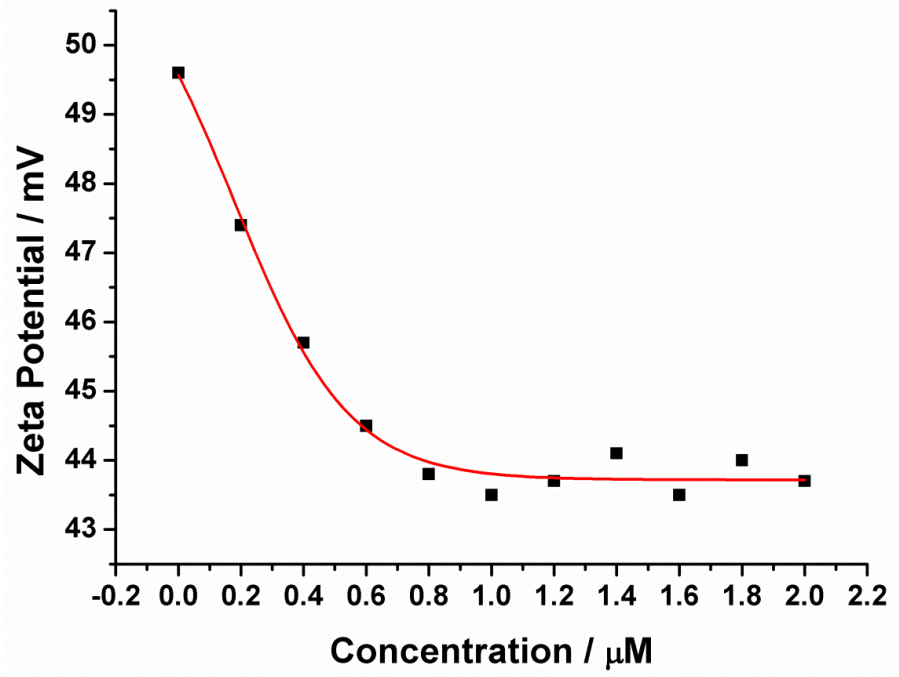

Figure S7 Dependence of $\zeta$ potential of $\mathrm{TbL}^{3+}(\mathbf{I})$ on the concentration of ssDNA-kit1. The concentration of $\mathrm{TbL}^{3+}(\mathbf{I})$ for all experiments was $150 \mu \mathrm{M}$, in $10 \mathrm{mM}$ Tris-HCl buffer $(\mathrm{pH}=7.4)$. 


\section{Luminescence spectra of $[\mathrm{TbL}(\mathrm{I})] \mathrm{Cl}_{3}$}
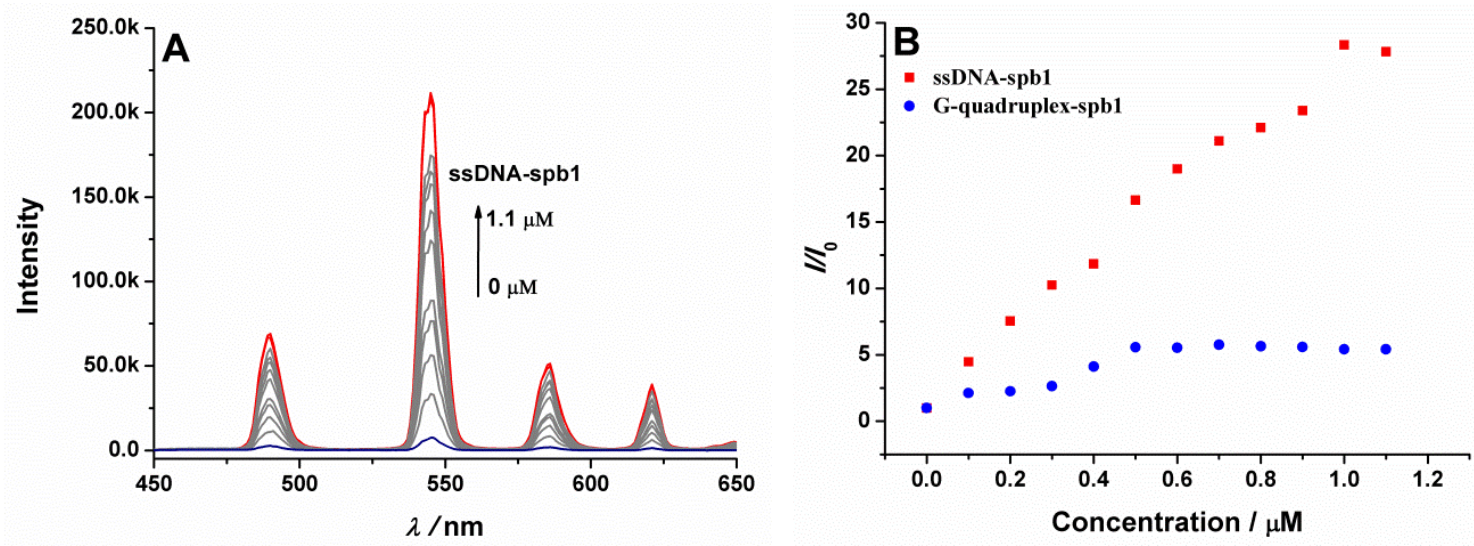

Figure S8 Luminescence spectra of $\mathrm{TbL}^{3+}(\mathbf{I})$ in the absence and presence of ssDNA-spb1 (A); $I / I_{0}$ evolution of $\mathrm{TbL}^{3+}(\mathbf{I})$ with increasing concentration of ssDNA-spb1 and G-quadruplex-spb1 (B). The concentration of $\mathrm{TbL}^{3+}(\mathbf{I})$ was $150 \mu \mathrm{M}$, in $10 \mathrm{mM}$ Tris-HCl buffer $(\mathrm{pH}=7.4), \lambda_{\mathrm{ex}}=260 \mathrm{~nm}$.
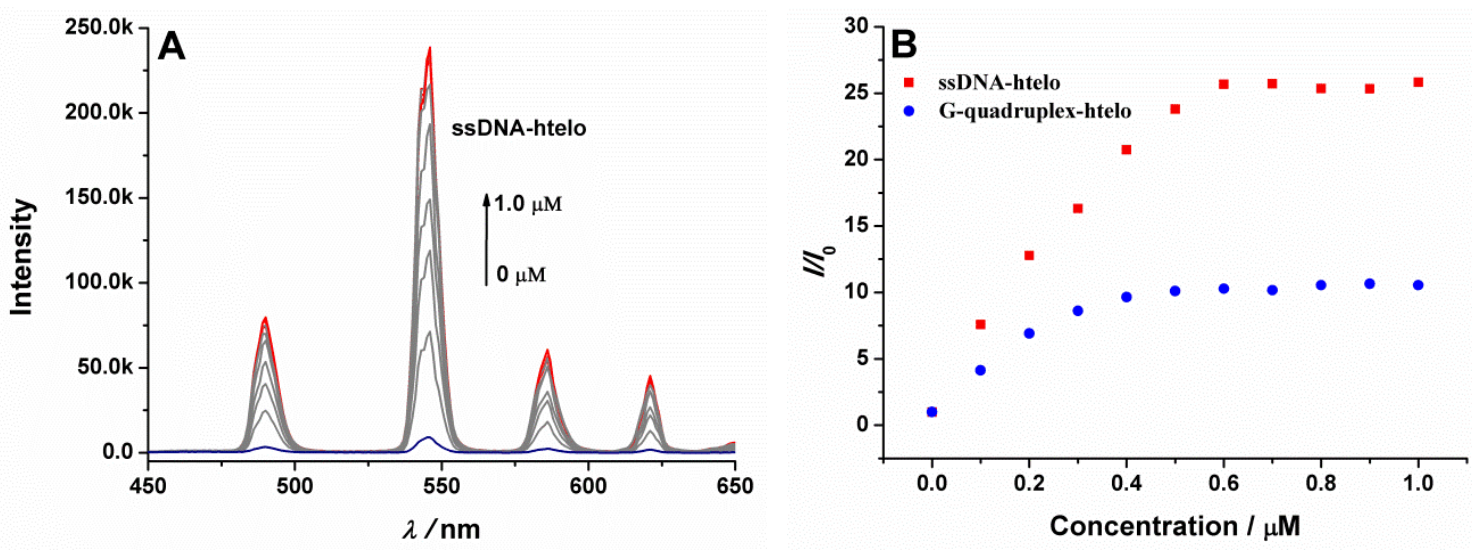

Figure S9 Luminescence spectra of $\mathrm{TbL}^{3+}(\mathbf{I})$ in the absence and presence of ssDNA-htelo (A); $I / I_{0}$ evolution of $\mathrm{TbL}^{3+}(\mathbf{I})$ with increasing concentration of ssDNA-htelo and G-quadruplex-htelo (B). The concentration of $\mathrm{TbL}^{3+}(\mathbf{I})$ was $150 \mu \mathrm{M}$, in $10 \mathrm{mM}$ Tris-HCl buffer $(\mathrm{pH}=7.4), \lambda_{\mathrm{ex}}=260 \mathrm{~nm}$.
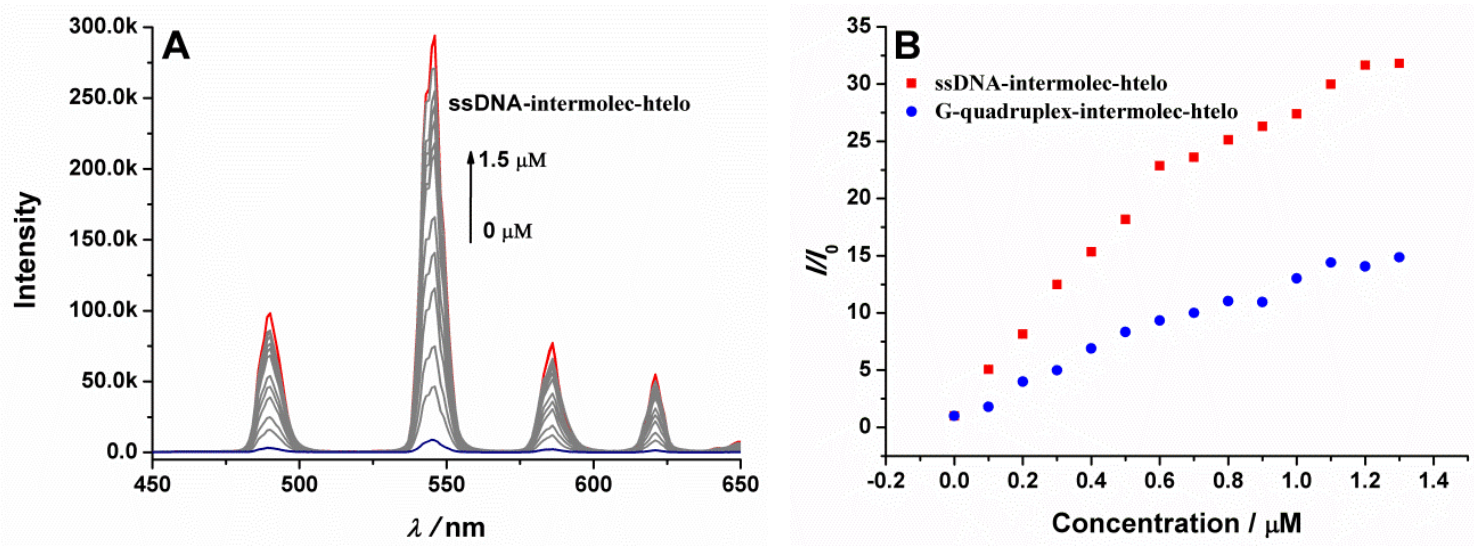

Figure S10 Luminescence spectra of $\mathrm{TbL}^{3+}(\mathbf{I})$ in the absence and presence of ssDNA-intermolec-htelo (A); $I / I_{0}$ evolution of $\mathrm{TbL}^{3+}(\mathbf{I})$ with increasing concentration of ssDNA-intermolec-htelo and G-quadruplex-intermolechtelo (B). The concentration of $\mathrm{TbL}^{3+}(\mathbf{I})$ was $150 \mu \mathrm{M}$, in $10 \mathrm{mM}$ Tris- $\mathrm{HCl}$ buffer $(\mathrm{pH}=7.4), \lambda_{\mathrm{ex}}=260 \mathrm{~nm}$. 


\section{CD spectra of various G-rich ssDNA}
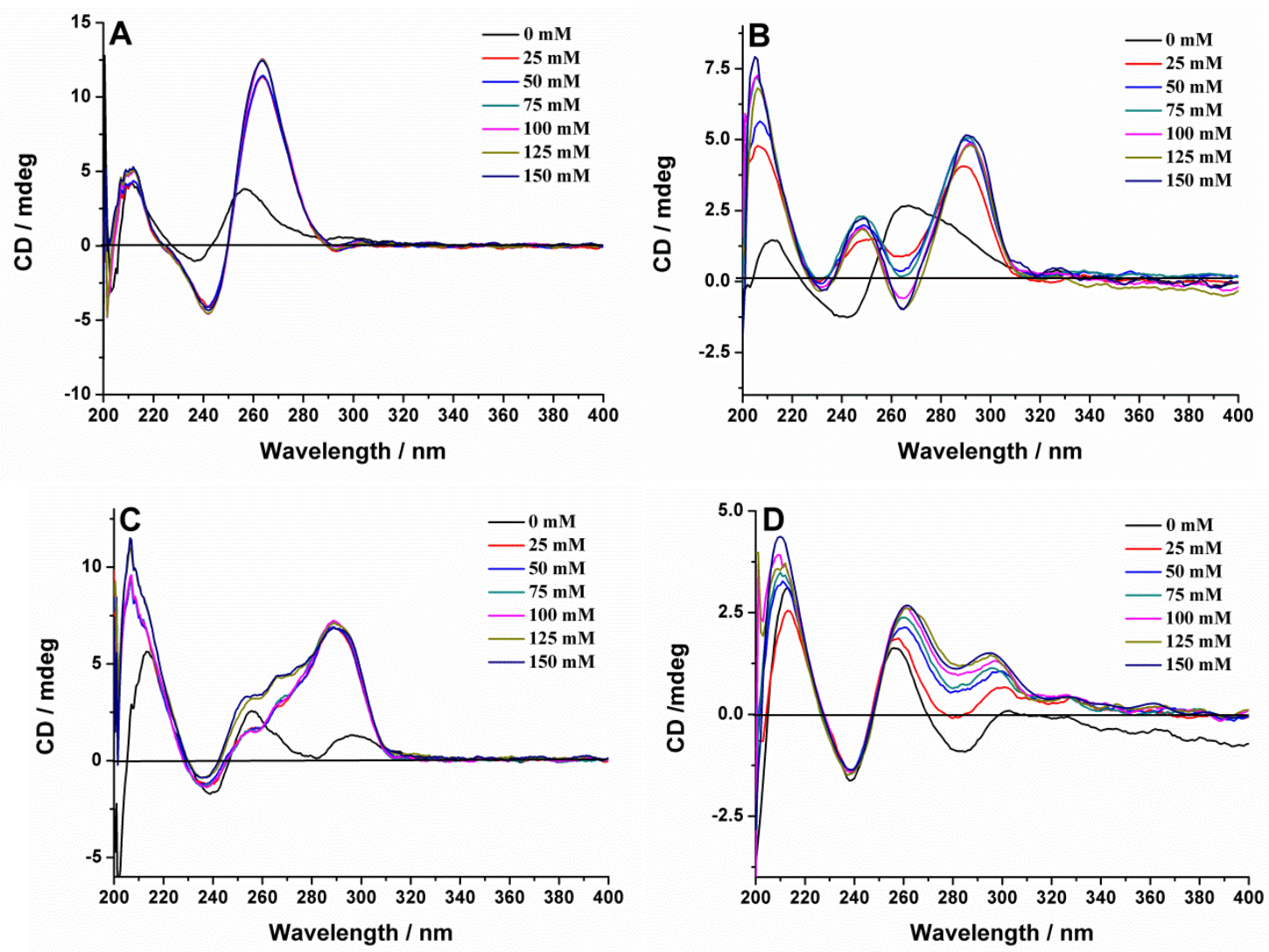

Figure S11 CD spectra of various G-rich ssDNA (kit1 (A), spb1 (B), htelo (C), intermolec-htelo (D)) in the absence and presence of $\mathrm{KCl}$ at different concentrations. The concentration of ssDNA was $1.0 \mu \mathrm{M}$, in $10 \mathrm{mM}$ Tris- $\mathrm{HCl}$ buffer $(\mathrm{pH}=7.4)$.

As shown in Figure S11, the spectra of G-quadruplex-kit1 are characteristic of parallel G-quadruplex with a positive peak at $\sim 265 \mathrm{~nm}$ and a negative peak at $\sim 240 \mathrm{~nm}$ (Figure S11A). In the case of G-quadruplex-spb1, the CD spectra displayed two positive peaks at $\sim 250$ and $\sim 290 \mathrm{~nm}$ respectively, indicating the formation of the anti-parallel G-quadruplex structures (Figure S11B). ssDNA-htelo and ssDNA-intermolec-htelo sequence can form a mixed-type propeller G-quadruplex structure and an intermolecular G-quadruplex structure respectively as proved by their CD spectra (Figure S11C, D). The above results are accord with that reported previously (Nat. Chem. 2013, 5, 182-186.). 


\section{Luminescence spectra of $[\mathrm{TbL}(\mathrm{I})] \mathrm{Cl}_{3} / \mathrm{ssDNA}$ mixtures}
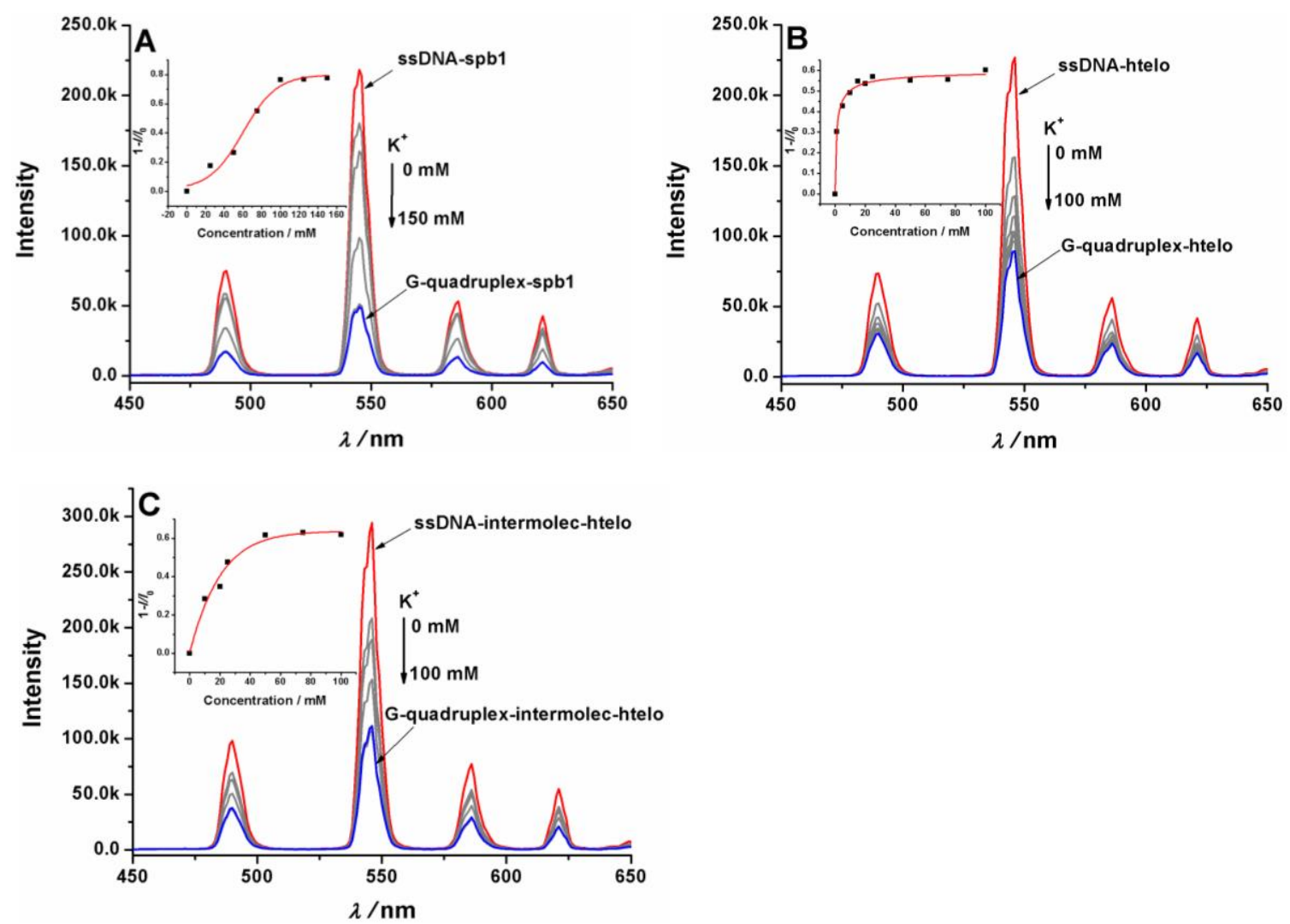

Figure S12 Luminescence spectra of $\mathrm{TbL}^{3+}(\mathbf{I}) / \mathrm{ssDNA}$ mixture in the absence and presence of $\mathrm{KCl}\left(\mathrm{TbL}^{3+}(\mathbf{I}) / \mathrm{spb} 1\right.$ (A), $\mathrm{TbL}^{3+}(\mathbf{I}) /$ htelo (B), $\mathrm{TbL}^{3+}(\mathbf{I}) /$ intermolec-htelo (C)). Inset: $1-I / I_{0}$ evolution of $\mathrm{TbL}^{3+}(\mathbf{I})$ with increasing concentration of $\mathrm{KCl}$. The luminescence intensity at $545 \mathrm{~nm}$ was chosen for analysis. The concentration of $\mathrm{TbL}^{3+}(\mathbf{I})$ and ssDNA were 150 and $1.0 \mu \mathrm{M}$, respectively, in $10 \mathrm{mM}$ Tris-HCl buffer $(\mathrm{pH}=7.4), \lambda_{\mathrm{ex}}=260 \mathrm{~nm}$. 


\section{Luminescence lifetime measurements}
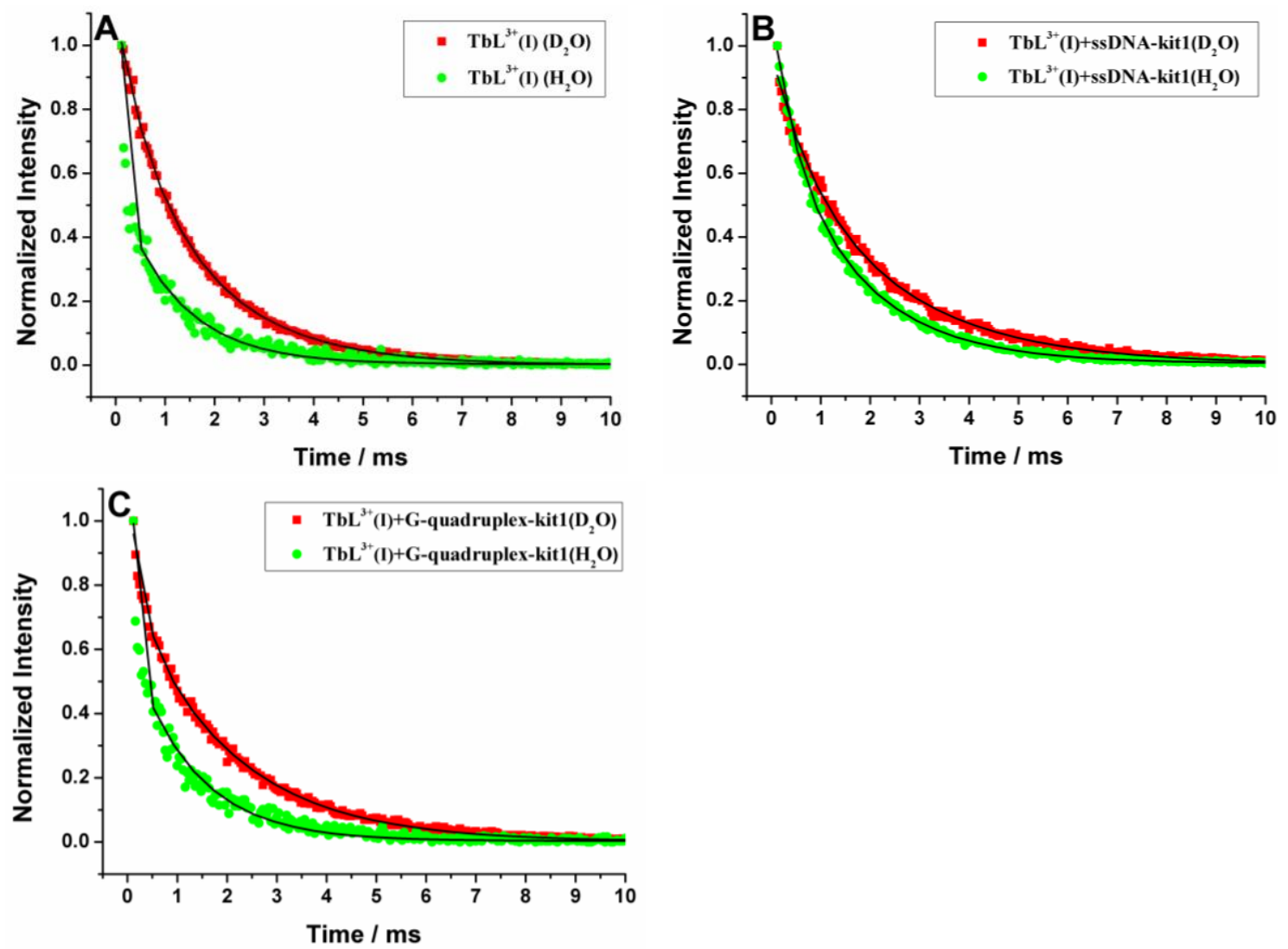

Figure S13 Luminescence decay curves of $\mathrm{TbL}^{3+}(\mathbf{I})$ (A), $\mathrm{TbL}^{3+}(\mathbf{I})+\operatorname{ssDNA}-k i t 1 \quad$ (B) and $\mathrm{TbL}^{3+}(\mathbf{I})+$ G-quadruplex-kit1 (C). Green: decay curve obtained in $\mathrm{H}_{2} \mathrm{O}$ dispersion; red: in $\mathrm{D}_{2} \mathrm{O}$ dispersion. The decay curves were fitted with double exponential curves (black). The concentration of $\mathrm{TbL}^{3+}(\mathbf{I})$ for all experiments was $150 \mu \mathrm{M}$, in $10 \mathrm{mM}$ Tris- $\mathrm{HCl}$ buffer $(\mathrm{pH}=7.4)$. The concentration of ssDNA was $1.0 \mu \mathrm{M}$.

As proved previously, the coordinated water reduces the luminescence lifetime of $\mathrm{Tb}(\mathrm{III})$ ion by the energy transfer from the excited state of $\mathrm{Tb}(\mathrm{III})$ to the higher $\mathrm{O}-\mathrm{H}$ vibration overtones of the water. Therefore, the luminescence lifetime of $\mathrm{TbL}^{3+}(\mathbf{I})$ should increase once the coordinated $\mathrm{H}_{2} \mathrm{O}$ molecules were replaced by $\mathrm{D}_{2} \mathrm{O}$. The number of water molecules coordinating to $\mathrm{Tb}(\mathrm{III})$ ion is represented by a value $q$, which can be estimated with Equation (1). (J. Chem. Soc., Perkin Trans. 2 1999, 3, 493-503)

$$
q=5.0 \times\left(K_{\mathrm{H} 2 \mathrm{O}}-K_{\mathrm{D} 2 \mathrm{O}}-0.06\right)
$$

In Equation (1), $K_{\mathrm{H} 2 \mathrm{O}}$ and $K_{\mathrm{D} 2 \mathrm{O}}$ represent the rate constants of luminescence decay, which are measured in $\mathrm{H}_{2} \mathrm{O}$ and $\mathrm{D}_{2} \mathrm{O}$ respectively (the decay curves are displayed in Figure $\mathrm{S} 13$ ). The luminescence lifetime of $\mathrm{TbL}^{3+}(\mathbf{I})$ in $\mathrm{H}_{2} \mathrm{O}(\tau=1.26 \mathrm{~ms})$ is much shorter than that in $\mathrm{D}_{2} \mathrm{O}(\tau=1.78 \mathrm{~ms})$. This result supports the quenching mechanism described above. The $q$ value was determined as 0.86 (Table S1), indicating that almost one $\mathrm{H}_{2} \mathrm{O}$ coordinated to $\mathrm{TbL}^{3+}(\mathbf{I})$. The luminescence lifetime of

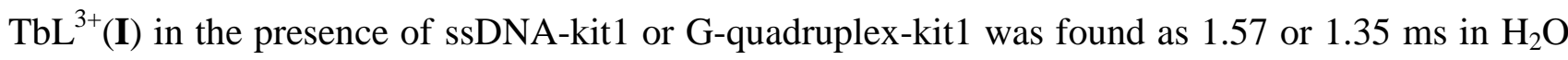


and 2.39 or $2.08 \mathrm{~ms}$ in $\mathrm{D}_{2} \mathrm{O}$. The longer luminescence lifetime is consistent with the observed enhancement in luminescence intensity. The $q$ values were obtained as 0.80 and 1.01 in the presence of ssDNA-kit1 and G-quadruplex-kit1 respectively. Apparently, no ligand exchange occurred with the coordinated water molecule during the binding of ssDNA or G-quadruplex to $\operatorname{TbL}^{3+}(\mathbf{I})$.

Table S1. Luminescence lifetime $\tau$ and rate constants $k$ determined for $[\mathrm{TbL}(\mathrm{I})] \mathrm{Cl}_{3}$ in $\mathrm{H}_{2} \mathrm{O}$ and $\mathrm{D}_{2} \mathrm{O}$, in the presence and absence of ssDNA-kit1 and G-quadruplex-kit1.

\begin{tabular}{cccc}
\hline Samples & $\boldsymbol{\tau}(\mathbf{m s})$ & $\boldsymbol{k}\left(\mathbf{m s}^{-1}\right)$ & $\boldsymbol{q}$ \\
\hline $\operatorname{TbL}^{3+}(\mathbf{I})\left(\mathrm{H}_{2} \mathrm{O}\right)$ & 1.26 & 0.79 & 0.86 \\
$\operatorname{TbL}^{3+}(\mathbf{I})(\mathrm{D} 2 \mathrm{O})$ & 1.78 & 0.56 & \\
$\mathrm{TbL}^{3+}(\mathbf{I})+$ ssDNA-kit1 $\left(\mathrm{H}_{2} \mathrm{O}\right)$ & 1.57 & 0.64 & 0.80 \\
$\mathrm{TbL}^{3+}(\mathbf{I})+$ ssDNA-kit1 (D2O) & 2.39 & 0.42 & \\
$\mathrm{TbL}^{3+}(\mathbf{I})+\mathrm{G}-$ quadruplex-kit1 $\left(\mathrm{H}_{2} \mathrm{O}\right)$ & 1.35 & 0.74 & \\
$\mathrm{TbL}^{3+}(\mathbf{I})+\mathrm{G}-$ quadruplex-kit1 $\left(\mathrm{D}_{2} \mathrm{O}\right)$ & 2.08 & 0.48 & \\
\hline
\end{tabular}

